\title{
Descripción de una experiencia educativa inclusiva con alumnado universitario: Trabajando habilidades para el empleo
}

\section{Description of an inclusive educational experience: Working job skills}

\author{
Belén Suárez Lantarón \\ e-mail: mariabelen.suarez@um.es \\ Universidad de Murcia. España \\ Irina S. Castillo Reche iD \\ e-mail: irinasherezade.castillo@um.es \\ Universidad de Murcia España
}

\section{Resumen}

La universidad del siglo XXI exige una formación cultural, comprendiendo bajo ese término un concepto y proceso más amplios de la formación integral con mayor compromiso social. En este nuevo contexto van surgiendo nuevas metodologías donde los estudiantes toman mayor protagonismo en el proceso de enseñanzaaprendizaje. Bajo esas premisas se presenta este proyecto educativo, cuyo objetivo final es promover la cooperación educativa y las tareas de aprendizaje significativo entre jóvenes con discapacidad intelectual y alumnado del grado de Educación Social. La metodología utilizada para su desarrollo se basa en el aprendizaje y servicio, pues sitúa al estudiante en el centro del proceso enseñanza-aprendizaje, desarrollando el crecimiento personal y comunitario a través de la experiencia activa, comprometida y reflexiva. Los resultados obtenidos han sido satisfactorios, muestran que se ha logrado un aprendizaje holístico que une teoría y práctica, así como desarrollar competencias profesionales y afectivas. Nos sentimos satisfechos del logro alcanzado, no solo en cuanto a resultados de aprendizaje, que son importantes, sino en mayor medida porque la actividad ha logrado el empoderamiento de nuestros estudiantes, creyendo en su capacidad de lograr cosas, sobre todo los alumnos y alumnas con discapacidad intelectual, que en muchos casos tienen una baja autopercepción de sus posibilidades y dudan de sus capacidades para afrontar o resolver determinadas situaciones.

Palabras clave: aprendizaje-servicio; discapacidad intelectual; educación inclusiva; educación social; metodologías activas; universidad.

\section{Abstract}

The XXI century University demands cultural training. This term comprises a broader concept and process of comprehensive education with greater social commitment. In this context, new methodologies are emerging in which students take greater prominence in the teaching-learning process. This educational project is presented under those premises and is aimed at promoting educational cooperation and significant learning tasks between young people with intellectual disabilities and students of the Social Education degree. The methodology used for its development is based on learning and service, because it places the student at the centre of the teachinglearning process, developing personal and community growth through active, committed and reflective experience. The results obtained are satisfying. They show that a holistic learning has been achieved, which unites theory and practice as well as the development of professional and affective competences. We are satisfied with the goal achieved, not only in terms of learning outcomes, which are important, but even more because the activity has achieved the empowerment of our students, who have believed in their ability to achieve things, especially the students with cognitive disabilities, who, in many cases, have a low self-perception of their possibilities and doubt their capabilities to face or resolve certain situations.

Keywords: service-learning; intelectual disability; inclusive education; social education: active methodologies; university.

Cómo referenciar este artículo / How to reference this article:

Suárez, B., \& Castillo, I. S. (2020). Descripción de una experiencia educativa inclusiva con alumnado universitario: Trabajando habilidades para el empleo. Tendencias Pedagógicas, 35, 2020, pp. 130-152. doi: $10.15366 /$ tp2020.35.11 


\section{Introducción}

Desde la construcción del EEES han sido numerosas las transformaciones sufridas en las universidades españolas, incluido un cambio en el papel que juega el estudiante en el proceso de enseñanzaaprendizaje (Ruiz y García, 2019; Silva y Maturana, 2017), lo que ha supuesto pasar de enfocarse en la adquisición de información a hacerlo en la adquisición de competencias y destrezas, tanto específicas como genéricas (Gil, 2012; Mateo y Vlachopulos, 2013; Vergara, 2012).

En la misma línea, autores como Aramburuzabala, Cerrillo y Tello (2015), García, De la Calle, Valbuena y De Dios (2016) o González, Jover y Martínez (2018) inciden en que la formación universitaria debe participar en la preparación de personas socialmente responsables.

Además, como exponen Fernández, Veliz y Ruiz (2016), la universidad del siglo XXI exige una formación cultural, término que abarca un concepto y proceso más amplios de la formación integral. Como explica Díaz (2012, p. 224): «la formación cultural establece relaciones con otros énfasis formativos, es el caso de la formación política, ciudadana, cívica, ecológica, entre otras, cada una orientando el desarrollo de la persona hacia una meta determinada».

Por tanto, coincidimos con Vázquez, Liesa y Lozano (2012) en que la optimización de la calidad del aprendizaje académico de los estudiantes universitarios y su formación integral como personas socialmente responsables se evidencia como fin primordial de toda formación universitaria. En palabras de Batlle (2011, p. 52): «el verdadero éxito de la educación consiste en formar buenos ciudadanos capaces de mejorar la sociedad y no sólo su currículum personal».

Es en este nuevo contexto donde van surgiendo nuevas metodologías en las que los estudiantes toman mayor protagonismo en el proceso de enseñanza-aprendizaje, que buscan su formación integral y socialmente responsable y que proponen resolver situaciones profesionales reales o ajustadas a situaciones que pueden darse en la vida real como, por ejemplo: el aprendizaje basado en proyectos, los proyectos sociales, el aprendizaje por retos o el aprendizaje-servicio.

\section{Fundamentación teórica}

\subsection{Universidad y discapacidad intelectual}

En los últimos años, las instituciones de educación superior han trabajado para hacer más accesible e inclusiva la formación que ofertan con acciones como la creación de servicios de atención al alumnado con discapacidad, la promoción de ayudas y becas o la accesibilidad de edificios, aulas y recursos.

Estos esfuerzos se reflejan en los datos que presentan los informes elaborados por la Fundación Universia ${ }^{1}$ de 2008 a 2018, donde se observa un incremento de los alumnos/as que encontrándose en situación de discapacidad se matriculan en la universidad.

Aun así, el porcentaje según el último de estos informes se sitúa en 1,5\% del total de estudiantes matriculados. Y de este grupo, la mayor parte $(55,9 \%)$ se encuentra en situación de discapacidad física, mientras que un 25,5\% tiene una discapacidad psicosocial, intelectual o del desarrollo.

Cerrillo, Izuzquiza y Egido (2013) ya señalaban que el desafío de la inclusión universitaria tiene «especial envergadura» en el caso de las personas con discapacidad intelectual, pues parece que las instituciones han emprendido acciones focalizadas en la supresión de barreras y la accesibilidad para personas con discapacidad física o sensorial.

Esta tendencia se puede observar en el desarrollo de trabajos de investigación y prácticas educativas o de innovación docente. Mientras que se pueden encontrar numerosos trabajos enfocados en la

\footnotetext{
1 Serie de estudios denominados «Universidad y discapacidad» accesibles en la página web de la Fundación Universia: https://www.fundacionuniversia.net/seccion/proyectos/informes-estudios/
} 
inclusión de personas con discapacidad en la universidad, el número disminuye cuando se centran en la discapacidad intelectual (proponemos algunos ejemplos de estos últimos en la Tabla 1).

Tabla 1.

Trabajos sobre discapacidad intelectual y universidad

Cerrillo, R. (2012). Transformación social en la universidad motivada por la inclusión de personas con discapacidad intelectual. En Actas Congreso Internacional de Formación del Profesorado (AUFFOP), celebrado en Valladolid en diciembre de 2012 (p. 179).

Cerrillo, R., Izuzquia, D. y Egido, I. (2013). Inclusión de jóvenes con discapacidad intelectual en la universidad. Revista de investigación en educación, 11 (1), 41-57.

De Andrés, S. y González, R. (2012). Comunicación inclusiva: una experiencia en creación de campanas sobre discapacidad intelectual. Área abierta, 12 (1), 1-15.

FEAPS (2009). La educación que queremos. Situación actual de la inclusión educativa en España. Madrid, España: FEAPS

Gallardo, A. (2012). Universidad y discapacidad intelectual. Actas de las IX Jornadas inclusión de los estudiantes con discapacidad en la universidad: necesidades y demandas, celebrado en Madrid en mayo de 2011 (pp. 145-164).

García, F., Berasategui, A. y Viejo, P. (2013). Discapacidad intelectual y universidad: una apuesta por la integración. Revista de padres y maestros, 354, 11-15.

Izuzquia, D. (2012). El valor de la inclusión educativa de jóvenes con discapacidad intelectual en las instituciones de educación superior: el programa Promentor. Bordón, Revista de pedagogía, 64 (1), 109-125.

Izuzquia, D., Egido, I. y Cerrillo, R. (2013). Diez años de formación para el empleo de personas con discapacidad intelectual en la universidad: balance y perspectiva. Revista Iberoamericana de educación, 63, 127-138.

Reyes, M. E. (2017). Somos uno más: programa educativo y social para jóvenes con discapacidad intelectual en la universidad iberoamericana. En A. Rodríguez (Coord.) Prácticas innovadoras inclusivas: retos y oportunidades (pp. 403-410). Oviedo, España: Universidad de Oviedo.

Ruiz, S., Rodríguez, O. y Bonilla, M. (2017). Formación inclusiva en entornos de educación superior para personas con discapacidad intelectual. En A. Rodríguez (Coord.) Prácticas innovadoras inclusivas: retos y oportunidades (pp. 403-410). Oviedo, España: Universidad de Oviedo.

Valenzuela, C., Barría, S., Díaz, A., Arcos, M. y Chacana, C. (2017). Resultados evaluación por competencias bajo situaciones simuladas en jóvenes en situación de discapacidad intelectual. En A. Rodríguez (Coord.) Prácticas innovadoras inclusivas: retos y oportunidades (pp. 403-410). Oviedo, España: Universidad de Oviedo. Verdugo, M. A. y Rodríguez, A. (2012). La educación inclusiva en España desde la perspectiva de alumnos con discapacidad intelectual, de familias y de profesionales. Revista de Educación, 355, 450-470.

Vilà, M., Pallisera, M. y Fullana, J. (2012). La inclusión laboral de jóvenes con discapacidad intelectual: un reto para la orientación pedagógica. REOP, 23 (1), 85-93.

Fuente: elaboración propia.

Entre las razones por las que las universidades no han atendido en el pasado las necesidades del colectivo con discapacidad intelectual, Cerrillo et al. (2013, p. 44) refieren las siguientes: (i) pervive un contexto universitario y social todavía excluyente; (ii) no han existido iniciativas legislativas que hayan regulado adecuadamente las demandas de formación de esta población; (iii) diseñar e implementar programas ajustados a las características y necesidades de estas personas son tareas muy complejas que exigen formación del profesorado universitario para una educación inclusiva.

No obstante, no queremos ser pesimistas, sino pensar que se debe seguir trabajando en esta línea, por ejemplo, con iniciativas como la convocatoria realizada por la ONCE para el desarrollo de programas universitarios de formación para el empleo dirigido a jóvenes con discapacidad intelectual inscritos en el Sistema de Garantía Social, en la que se ha incrementado el número de universidades participantes desde su primera edición en el curso 2017/18.

Compartimos la idea de Cerrillo et al (2013) de que son muchos los beneficios de la inclusión, tanto para el alumnado en situación de discapacidad (sociales, afectivos y de equilibrio personal relativos al sentimiento de no exclusión) como para el resto del alumnado (cambio de mentalidad sobre la discapacidad, enriquecimiento personal, incremento del compromiso social).

Estas razones invitan a desarrollar políticas y acciones inclusivas en el entorno universitario: la inclusión favorece una universidad más diversa y, por tanto, más rica. Además, se ofrecen 
oportunidades de crecimiento y enriquecimiento personal a los jóvenes con discapacidad intelectual, así como al conjunto de la comunidad universitaria.

\subsection{La metodología aprendizaje-servicio}

El aprendizaje-servicio (en adelante ApS), a pesar de que hace ya unos cuarenta años que se viene implementando, en la actualidad aún es concebido como una propuesta innovadora (Francisco y Moliner, 2010).

Rápidamente se han extendido, a nivel internacional, experiencias que siguen la premisa de unir en una sola actividad educativa el aprendizaje y el servicio. A pesar de dicha trayectoria, como refleja el trabajo de autores como Batle (2011), Capella, Zorrilla y Gil (2018) o Puig (2015), no existe unanimidad en cuanto al término (aprendizaje servicio, aprendizaje-servicio, aprendizaje y servicio, aprendizaje por servicio) ni al concepto (metodología, metodología activa, pedagogía activa, herramienta metodológica).

Sin embargo, tras revisar la bibliografía, se observa que hay coincidencia en cuanto a que resulta ser un medio eficaz para promover aprendizajes (contenidos curriculares) ligados a la práctica real 
(solucionar una necesidad o dar un servicio) y donde el alumnado es el protagonista de dicho proceso de enseñanza-aprendizaje.

En el ámbito universitario, esta metodología ha tenido buena acogida. Prueba de ello es la creación de la Red Nacional Universitaria de ApS o la investigación, innovación y práctica desarrolladas al respecto (algunos ejemplos se recogen en la Tabla 2).

Tabla 2.

Algunos trabajos desarrollados sobre ApS en la universidad

Álvarez, J. L., Martínez, M. J., González, H. y Buenestado, M. (2017). El aprendizaje-servicio en la formación del profesorado de las universidades españolas. Revista española de pedagogia, 75 (267), pp. 199217. doi: 10.22550/REP75-2-2017-02.

Arratia, A. (2008). Ética, solidaridad y «aprendizaje servicio» en la educación superior. Acta Bioetbica, 14 (1), pp. 61-67.

Batlel, R. (2011). ¿De qué hablamos cuando hablamos de aprendizaje-servicio? Crítica, 972, pp. 49-54.

Chiva, O., Capella, C. y Pallarés, M. (2018). Investigación-acción sobre un programa de aprendizajeservicio en la didáctica de la educación física. Revista de investigación educativa, 36 (1), 277-293. doi: 10.6018/rie.36.1.270581.

Chiva, O. y Gil, J. (Eds.) (2018). Aprendiraje-servicio universitario. Modelos de intervención e investigación en la formación inicial docente. Barcelona, España: Octaedro.

Escofet, A., Folgueiras, P., Luna, E. y Palau, B. (2016). Elaboración y validación de un cuestionario para la valoración de proyectos de aprendizaje-servicio. Revista mexicana de investigación educativa, 21 (70), pp. 929-949.

Ferran, A. y Guinot, C. (2012). Aprendizaje-servicio: propuesta metodológica para trabajar competencias. Portularia, 12 (Extra), pp. 187-195. doi: 10.5218/PRTS.2012.0020.

García, M. y Benítez, R. (2014). Comprometiéndonos con «nuestra escuela»: un proyecto de Aprendizaje-Servicio para una formación del profesorado inclusiva. Revista nacional e internacional de educación inclusiva, 7 (2), pp. 69-83.

Gutiérrez, M. y Moreno, P. (2018). El aprendizaje servicio como metodología para la formación integral de los estudiantes universitarios. EDETANLA, 53, pp. 184-202.

Mayor, D. y Rodríguez, D. (2016). Aprendizaje-Servicio y prácticas docentes: una relación para el cambio educativo. Revista de investigación educativa, 34 (2), pp. 535-552. doi: 10.6018/rie.34.2.231401.

Puig, J. M. (Coord.) (2015). ¿Cómo realizar un proyecto de aprendizaje servicio?11 ideas clave. Barcelona, España: Octaedro.

Puig, J. M., Martín, X. y Rubio, L. (2017). ¿Cómo evaluar proyectos de aprendizaje servicio? Voces de la educación, 2 (2), pp. 122-132.

Santamaría, I. y Martínez, A. (2018). El aprendizaje servicio, interculturalidad y justicia social: experiencias disruptivas y transformadoras con futuras maestras de educación infantil y primaria. Revista Qurriculum, 31, pp. 97-118. doi: 10.25145/j.qurricul.2018.31.005

Vázquez, S., Liesa, M. y Lozano, A. (2017). Recreos cooperativos e inclusivos a través de la metodología de Aprendizaje-Servicio. Revista electrónica interuniversitaria de formación del profesorado, 20 (1), pp. 173-185. doi: 10.6018/reifop.20.1.213181.

Vergara, D. (2012). Una experiencia educativa de aprendizaje cooperativo en la universidad. Profesorado, 16 (2), pp. 387-402.

Zayas, B., Gonzálvez, V. y Gracia, J. (2019). La dimensión ética y ciudadana del aprendizaje servicio: una apuesta por la institucionalización en la educación superior. Revista Complutense de Educación, 30 (1), pp. 1-15. doi: 10.5209/RCED.55443.

Fuente: elaboración propia.

La justificación de la buena acogida que esta metodología ha tenido en todas las etapas educativas, incluida la etapa universitaria, se sustenta en las características y las ventajas que a continuación resumimos:

- Metodología activa, experiencial y de servicio a la comunidad. (Aramburuzabala, 2013; Batlle, 2011; Capella y Zorrilla, 2018; Mayor y Rodríguez, 2016; Mendia, 2016)

- Metodología proactiva, cooperativa, problematizadora, relacional, reflexiva y transformadora. (Álvarez, Martínez, González y Buenestado, 2017) 
- Implica al alumnado en su formación. Sitúa al estudiante como protagonista de su propio desarrollo. (Batlle, 2011; Mayor y Rodríguez, 2016; Mendía, 2012; Ochoa, Pérez y Salinas, 2018)

- Pone en práctica contenidos teóricos a la vez que promueve la solidaridad y la responsabilidad. Relaciona contenidos curriculares con el servicio a la comunidad. Acerca el aprendizaje a la vida real. (Folgueiras, Luna y Puig, 2010; Mendía, 2016; Álvarez et al., 2017)

- Promueve aprendizajes significativos, útiles y relevantes. Motiva y da sentido al aprendizaje. (Aramburuzabala, 2013; Mayor y Rodríguez, 2016; Mendía, 2012)

- Se adquieren actitudes y competencias transversales difíciles de obtener de otro modo. Promueve capacidades, actitudes y valores. (Folguerias et al., 2010; García y Benítez, 2014; Ochoa et al., 2018; Rodríguez, De la Herrán y Cortina, 2015)

- Promueve competencias como la resolución de problemas, la adaptación a los cambios, el trabajo en equipo y colaborativo, la autonomía y la empatía. Mejora la convivencia. Favorece la reflexión crítica. (Álvarez et al, 2017; Piñana, 2018)

- Genera sentimientos de autoeficacia, autoestima, liderazgo y habilidades para trabajar con otros. (Mendía, 2012)

- Los estudiantes juegan un papel relevante que influye en su empoderamiento. Dota de «emoción» al proceso de enseñanza-aprendizaje. (Folgueiras et al., 2010; García y Benítez, 2014)

- Desarrolla la capacidad asociativa y estimula el emprendimiento social. (Mendía, 2012)

\section{Contextualización del proyecto-experiencia}

La empleabilidad de las personas en situación de discapacidad sigue siendo un reto para las instituciones y administraciones, no solo en nuestro en país. De hecho, la Comisión Europea (2010) destaca que, aunque las personas con discapacidad representan la sexta parte de la población en edad laboral de la UE, su nivel de empleo es comparativamente bajo y por ello promueve (Estrategia 2010-2020) un compromiso en la mejora de la accesibilidad de estas personas al mercado laboral y en su formación para ello.

En esta línea, la Universidad de Murcia oferta un curso de estudios propios denominado Todos somos Campus ${ }^{2}$ destinado a jóvenes en situación de discapacidad intelectual (se utiliza este término siguiendo el ejemplo de Plena Inclusión, organización que representa en España a las personas con discapacidad intelectual o del desarrollo), con el objetivo de preparar a estos jóvenes para su inserción laboral y brindarles la oportunidad de ir a la universidad y participar de la vida universitaria. Dicho curso consta de un periodo de formación que se imparte en las aulas de la Facultad de Educación y de un periodo práctico (realización de prácticas en empresas).

En esta su segunda edición, los contenidos se han distribuido en dos cursos académicos, de 33 créditos cada uno, comenzando en 2018/19. El primer curso es de introducción al entorno laboral (con una duración aproximada de siete meses, iniciándose en noviembre y finalizando en mayo, momento en que comienza la parte práctica) y el segundo curso se centra en conocimientos más especializados sobre empleo. Ambos forman parte del programa de Estudios Propios de la Universidad

\footnotetext{
2 Este curso se financia con Fondos Sociales Europeos y la Fundación ONCE. Lo solicita la Universidad de Murcia a través del Vicerrectorado de Estudiantes, y el de Empleo y Estudios. Los Servicios que están implicados son el de Atención a la Diversidad y Voluntariado (ADyV) y el Centro de Orientación e Información para el Empleo (COIE).
} 
de Murcia, con todo lo que ello supone en cuanto a reconocimiento de su superación, organización y gestión del mismo.

Los contenidos se encuentran repartidos en diferentes bloques a lo largo de los dos cursos programados. En el Anexo A se recoge la distribución de los contenidos del primer curso, en el que se sitúa la experiencia que se describe.

En base a las premisas del marco teórico (promover la inclusión y promover la formación de personas socialmente responsables) surge la idea de desarrollar un proyecto/experiencia educativa que articule tareas de aprendizaje significativo que hagan sentir al alumnado partícipe de su formación, planteando la solución a situaciones profesionales que podrían darse en la vida real y que, además, sea una experiencia inclusiva.

Las docentes que promueven la experiencia imparten clase tanto en el curso Todos Somos Campus como en el Grado de Educación Social. Dado que entre los contenidos de aprendizaje que el alumnado de Todos Somos Campus debe adquirir están las competencias para afrontar una entrevista de trabajo y que el alumnado del Grado de Educación Social debe adquirir competencias relacionadas con saber evaluar, se proponen como objetivo trabajar ambas cuestiones desde una perspectiva inclusiva.

Se busca utilizar una metodología activa y participativa, seleccionando el proyecto social como opción más adecuada, por considerarlo una herramienta de innovación y aprendizaje (Fernández y Ponce de León, 2016).

Se elige el proyecto por tratarse de un nivel reducido y más específico que un programa o un plan, con menor duración que estos y mayor concreción y operatividad, siendo su finalidad la mejora de una situación de partida (Fernández y Ponce de León, 2016).

Para estos autores, poner en marcha un proyecto social supone «un ejercicio de comprensión de la realidad en la que se enmarca [...] un proceso dinámico cuya finalidad no es otra que la superación de una problemática o necesidad que ha motivado su puesta en marcha» (p. 29). Implica un método de trabajo basado en el rigor científico como elemento central en la consecución del éxito; ya que su diseño, planificación, ejecución y evaluación han de estar guiados por la coherencia y la flexibilidad.

Tras la revisión de textos sobre proyectos o experiencias realizas con similar intención, concretamos esta metodología en el desarrollo de un proyecto de aprendizaje y servicio. Decisión que se sustenta en el hecho de que dicha metodología, activa y experimental, sitúa al estudiante en el centro del proceso de enseñanza-aprendizaje y desarrolla el crecimiento personal y comunitario a través de una experiencia activa, comprometida y reflexiva (Montanero, 2019).

\subsection{Participantes}

En el diseño e implementación de esta experiencia han participado:

- 2 docentes que imparten clase en el Grado de Educación Social, en las asignaturas de «Evaluación de servicios y profesionales de la Educación Social» (materia de 6 créditos ETCS de carácter obligatorio en $3^{\circ}$ curso) y de «Procesos y condiciones para el desarrollo de proyectos» (materia de 6 créditos de carácter obligatorio en $2^{\circ}$ curso). Ambas docentes también imparten clase en el curso Todos Somos Campus, concretamente en habilidades emocionales en la empresa y entrenamiento cognitivo para el empleo (autoestima, autoconocimiento, autocontrol, confianza, afrontamiento de resultados, lenguaje y expresión comunicativa, etc.).

- 1 técnico de apoyo que acompaña siempre en el aula al alumnado de Todos Somos Campus.

- 48 alumnos y alumnas de $3^{\circ}$ curso de Educación Social que cursan y han cursado las asignaturas antes descritas, distribuidos en ocho grupos de trabajo.

- 16 alumnos y alumnas en situación de discapacidad intelectual de $1^{\circ}$ curso de Todos Somos Campus II. 


\section{Procedimiento}

El procedimiento seguido para el diseño e implementación de la experiencia ha tenido en cuenta la referencia de Capella, Zorrilla y Gil (2018), quienes señalan tres momentos cruciales en el diseño e implementación de un programa de ApS:

1. Un periodo inicial, que implica la preparación del grupo de trabajo y el proyecto a desarrollar.

2. Una etapa intermedia que comporta la implementación del servicio.

3. Una fase final, que abarca los procesos de reflexión y evaluación.

Describimos a continuación, en mayor detalle, cada una de estas etapas para el caso concreto de esta experiencia:

\subsection{Periodo inicial: diseño de la experiencia}

El proyecto se plantea con la intención de implementar una experiencia de enseñanza-aprendizaje en la Facultad de Educación de la Universidad de Murcia, que promueva la colaboración entre estudiantes de $3^{\circ}$ del Grado de Educación Social que cursan la asignatura de «Evaluación de servicios y profesionales de la Educación Social» y estudiantes del curso Todos Somos Campus.

Surge como propuesta para favorecer la educación inclusiva en el ámbito universitario, asumiendo como reto el hecho de que enseñar a estudiantes con características diferentes en un mismo centro y 
una misma aula no es una tarea fácil, pero tampoco imposible y que, como proponen García y Benítez (2014), este reto pasa por cambiar la forma de enseñar y organizar las actividades del aula.

Además de favorecer la colaboración entre alumnado con características diferentes se busca que, a través de dicha experiencia, adquieran las competencias establecidas en las materias que trabaja cada uno de los colectivos. Estas competencias se describen en la Tabla 3:

Tabla 3.

Competencias a adquirir por el alumnado

\begin{tabular}{|c|c|c|}
\hline & $\begin{array}{c}\text { ALUMNADO DE } 3^{\circ} \mathrm{DE} \\
\text { E. SOCIAL }\end{array}$ & $\begin{array}{c}\text { ALUMNADO CURSO } \\
\text { TODOS SOMOS CAM- } \\
\text { PUS }\end{array}$ \\
\hline COMPETENCIAS ESPECÍFICAS & $\begin{array}{l}\text { Ser capaces de aplicar conoci- } \\
\text { mientos de su trabajo o voca- } \\
\text { ción de una forma profesional y } \\
\text { poseer las competencias que } \\
\text { suelen demostrarse por medio } \\
\text { de la elaboración y defensa de } \\
\text { argumentos, resolución de pro- } \\
\text { blemas dentro del área de estu- } \\
\text { dio. } \\
\text { Desarrollar capacidades de aná- } \\
\text { lisis de realidades sociales y edu- } \\
\text { cativas y de elaboración de pro- } \\
\text { yectos de intervención en rela- } \\
\text { ción con los diferentes contex- } \\
\text { tos, sujetos y colectivos con que } \\
\text { trabaja la educación social. }\end{array}$ & $\begin{array}{l}\text { Autoconocimiento y auto- } \\
\text { estima. } \\
\text { Motivación para el trabajo. } \\
\text { Confianza. } \\
\text { Afrontamiento de resulta- } \\
\text { dos. }\end{array}$ \\
\hline COMPETENCIAS GENERALES & $\begin{array}{l}\text { Capacidad para trabajar en } \\
\text { equipo y para relacionarse con } \\
\text { otras personas del mismo o dis- } \\
\text { tinto ámbito personal. }\end{array}$ & $\begin{array}{l}\text { Comunicación interperso- } \\
\text { nal. } \\
\text { Actitud cooperativa. Tra- } \\
\text { bajo en equipo. } \\
\text { Comunicación oral y es- } \\
\text { crita. } \\
\text { Lenguaje y expresión comu- } \\
\text { nicativa. }\end{array}$ \\
\hline
\end{tabular}

Fuente: Elaboración propia.

Esperamos, además, que con las acciones a planificar y desarrollar no solo se dé respuesta a esta necesidad, sino también se produzca un empoderamiento de sus destinatarios.

Los docentes observan en el alumnado de Todos Somos Campus (dentro de las competencias que deben adquirir) la necesidad de afrontar los retos que supone pasar por una entrevista de selección de personal (la mayoría son tímidos o vergonzosos, expresan miedo a no responder adecuadamente y sienten temor al fracaso ante esta tarea). De otra parte, el alumnado de Grado debe consolidar sus conocimientos relativos a la evaluación y sus instrumentos.

Los docentes consideran la posibilidad de desarrollar una experiencia en la que los estudiantes de Educación Social atiendan la necesidad de los compañeros de Todos Somos Campus y les ayuden a afrontar una entrevista de trabajo.

Tomada la decisión entre docentes y técnico de trabajar estas cuestiones, se lleva a cabo la primera reunión informativa con el alumnado de $3^{\circ}$ de Educación Social, al que se propone participar en el diseño, implementación y evaluación de una práctica: una entrevista de selección de personal, en la que deben elaborar un cuestionario dirigido a personas con discapacidad intelectual contextualizado (diferentes perfiles profesionales) en una empresa y su posterior aplicación en una entrevista de selección de personal. Posteriormente, el mismo grupo de estudiantes deberá evaluar dicha herramienta, 
realizar un informe y aportar propuestas de mejora (competencias relacionadas con la asignatura de grado «Evaluación de servicios y profesionales de la Educación Social»).

\subsection{Etapa intermedia: implementación}

La experiencia se llevó a cabo en el segundo cuatrimestre del curso 2018/19, con una duración de dos semanas. Contó con cinco sesiones presenciales (sumando un total de ocho horas) para los estudiantes de Educación Social y dos sesiones presenciales (de dos horas cada una) para el desarrollo conjunto con el alumnado de Todos Somos Campus, además del tiempo de trabajo autónomo y de grupo invertido fuera de las aulas.

El cronograma con las sesiones y tareas desarrolladas en el aula, así como los objetivos que se pretenden lograr, se muestra en la Tabla 4.

Tabla 4.

Cronograma de sesiones desarrolladas

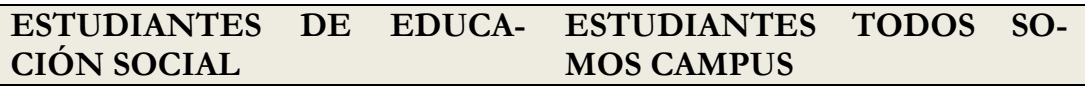

Práctica 1. Conocer los intereses, puntos fuertes y débiles que tenemos. Cómo podemos mejorarlos y elaborar un currículum -original- que destaque nuestras potencialidades.

Esta sesión la realizan de forma conjunta, colaborando dos estudiantes de Todos Somos Campus con un grupo (en total son 8 grupos formados por 6 estudiantes) de Educación Social.

1ª SESIÓN (2 horas) Partiendo de un guion elaborado previamente con los aspectos clave, y utilizando la técnica del grupo de discusión, se aportarán ideas sobre los puntos fuertes y débiles con que cada uno cuenta, cómo mejorar los puntos débiles que se reconocen y elaborar un currículum -original-. Además, los estudiantes de Todos Somos Campus aportan su punto de vista sobre cómo creen que debería ser un buen profesional de la Educación Social.

Objetivos: Desarrollar habilidades de comunicación y de colaboración. Trabajar el autoconocimiento y la autoestima.

Diseño de la Práctica 2. En base a los intereses detectados en la Práctica 1, constituirse como empresas. Elaborar un instrumento para seleccionar personal mediante una entrevista.

Esta actividad la llevan a cabo los estudiantes de Educación Social en los grupos de trabajo antes establecidos, cada uno de los cuales se constituirá como

\section{$2^{a}$ SESIÓN (1 hora) una empresa.}

Tiene como objetivo elaborar un instrumento con el que recoger información que permita seleccionar al candidato más adecuado en relación a los diferentes perfiles profesionales que señalaron los estudiantes de Todos Somos Campus, tomando como referencia la información recogida en la $1^{a}$ sesión.

El alumnado de Educación Social continúa con la construcción de la herramienta o instrumento para utilizar en

$3^{\text {a }}$ SESIÓN (2 horas) la entrevista de selección de personal. mentos de evaluación (cualitativos y cuantitativos) y ser capaces de elaborarlos. 


\begin{tabular}{|c|c|}
\hline & $\begin{array}{llllll}\begin{array}{l}\text { ESTUDIANTES } \\
\text { CIÓN SOCIAL }\end{array} & \text { DE } & \text { EDUCA- } & \begin{array}{l}\text { ESTUDIANTES } \\
\text { MOS CAMPUS }\end{array} & \text { TODOS } & \text { SO- }\end{array}$ \\
\hline $4^{\text {a }}$ SESIÓN (2 horas) & $\begin{array}{l}\text { Práctica 2. Elaborar la herramienta de selección de personal. Cada grupo (esta- } \\
\text { blecido como empresa) lleva a cabo las entrevistas de trabajo para seleccionar } \\
\text { personal. } \\
\text { Los estudiantes de Educación Social actúan como empleadores y los estudiantes } \\
\text { de Todos Somos Campus como candidatos que participan en dichas entrevistas } \\
\text { de selección. } \\
\text { Objetivo general: Colaborar y trabajar en equipo. Favorecer la participación y } \\
\text { desarrollar habilidades de comunicación. } \\
\text { Objetivo para el alumnado de Todos Somos Campus: Desarrollar la capacidad } \\
\text { para afrontar una entrevista de trabajo. } \\
\text { Objetivo para el alumnado de Educación Social: Implementar un instrumento } \\
\text { de evaluación y registro de información. Tomar decisiones. }\end{array}$ \\
\hline 5 SESIÓN (1 hora) & $\begin{array}{l}\text { Construcción de un instrumento de } \\
\text { evaluación con el que valorar el instru- } \\
\text { mento utilizado para la entrevista. Ela- } \\
\text { boración de un informe y propuestas } \\
\text { de mejora. } \\
\text { Objetivo: Aplicar el conocimiento so- } \\
\text { bre técnicas de evaluación en la prác- } \\
\text { tica. }\end{array}$ \\
\hline
\end{tabular}

Fuente: Elaboración propia.

\subsection{Fase final: reflexión y evaluación}

La evaluación es, en palabras de Fernández y Ponce de León (2016), uno de los momentos más decisivos, ya que permite comprobar con objetividad si se han logrado las metas propuestas. Para ello, la evaluación exige sistematización y rigor metodológico. Además, como indica Deeley (2016, p.109), los métodos tradicionales de evaluación no son adecuados para evaluar el aprendizaje-servicio, cobrando importancia otras técnicas, como la autoevaluación.

Con este propósito, tomamos ejemplo de la rúbrica elaborada por Puig, Martín y Rubio (2017) para analizar la calidad educativa del aprendizaje-servicio, la cual, como señalan los autores:

Persigue tres finalidades. La primera, facilitar la autoevaluación de las experiencias de aprendizaje-servicio que ya funcionaban, abriendo espacios para el debate sobre sus características pedagógicas y atendiendo al contexto y condiciones en las que estas se realizan. En segundo lugar, favorecer la optimización global o parcial de actividades que se han llevado a cabo y que los equipos educativos desean replicar, adaptar y mejorar. Y, por último, animar al diseño e implementación de actividades nuevas, desde centros educativos o entidades sociales que no tienen por qué tener tradición en aprendizaje-servicio (p. 125).

Como se recoge en la Tabla 5, esta rúbrica se organiza en diferentes dinamismos (elementos pedagógicos que representan una visión global de las experiencias de aprendizaje-servicio) y niveles que 
manifiestan el grado de desarrollo pedagógico (establece cuatro niveles: 1. Ignoradas, 2. Presentadas, 3. Decididas y 4. Descubiertas).

Tabla 5.

Rúbrica autoevaluación aprendizaje-servicio

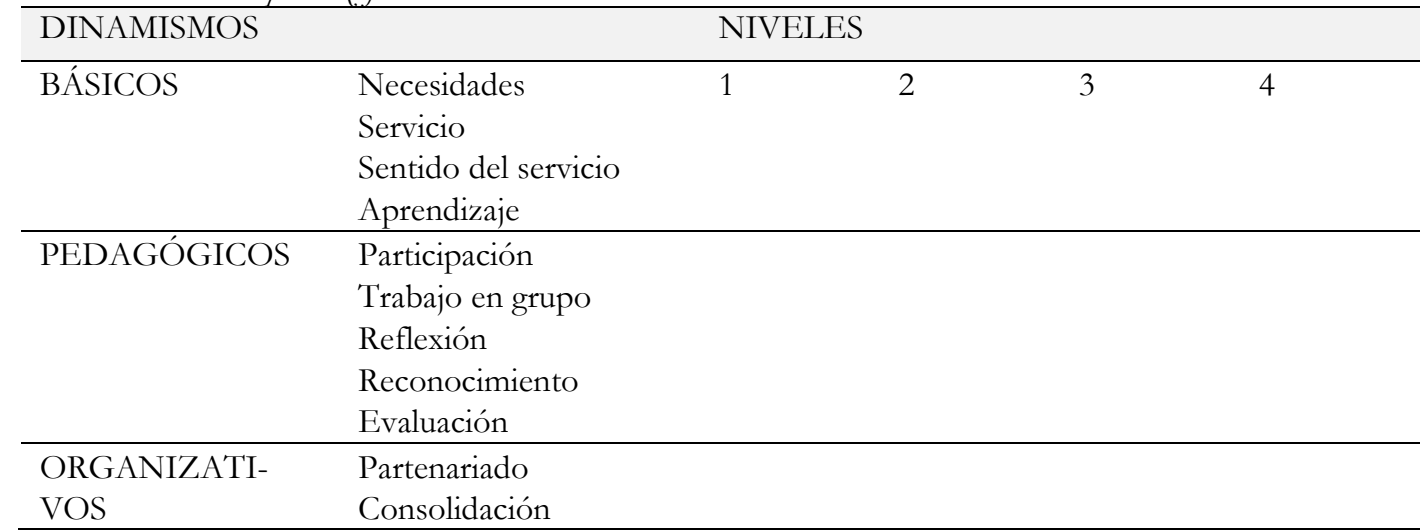

Fuente: Puig et al. (2017).

Para obtener la información se utiliza una metodología mixta apoyada en instrumentos cualitativos (la observación y el grupo de discusión) y cuantitativos (cuestionario), permitiéndonos obtener información al inicio, durante y al final del proyecto, estableciendo niveles de consecución de objetivos, detectando debilidades y fortalezas (ver Tabla 6). Además, estas técnicas de recogida de información y los informantes se han triangulado con el fin de aumentar la validez, permitiéndonos la comparación múltiple de un fenómeno único, así como obtener otra información no aportada en un primer nivel de lectura de la realidad (Pérez, 2011).

Tabla 6.

Relación de informantes e instrumentos de evaluación

\begin{tabular}{lccc} 
& OBSERVACIÓN & $\begin{array}{c}\text { GRUPO DE } \\
\text { DISCUSIÓN }\end{array}$ & CUESTIONARIO \\
\hline ESTUDIANTES DE GRADO & & $\mathrm{X}$ & $\mathrm{X}$ \\
\hline $\begin{array}{l}\text { ESTUDIANTES TODOS SO- } \\
\text { MOS CAMPUS }\end{array}$ & & $\mathrm{X}$ & $\mathrm{X}$ \\
\hline DOCENTES & $\mathrm{X}$ & $\mathrm{X}$ & \\
\hline TÉCNICO DE APOYO & $\mathrm{X}$ & $\mathrm{X}$ & \\
\hline
\end{tabular}

Fuente: Elaboración propia.

\subsubsection{La observación}

Esta técnica es considerada como un proceso riguroso para la investigación que permite describir situaciones y/o contrastar hipótesis (Fernández y Ponce de León, 2016; Pérez, 2011).

Se elige la observación participante pasiva (ya que el observador se encuentra inmerso en la situación a observar y permanece en el lugar donde se desarrolla la acción, aunque interactúa lo menos posible) y sistematizada, utilizando una rúbrica que permita recoger información al inicio, durante y al final del proyecto (registro y notas de periodo 1 , registro y notas de periodo 2 y registro y notas de 
periodo 3, anotando, además, fecha y hora, ver Tabla 7). Se completa con información obtenida mediante el diario de aula y las notas de campo.

Tabla 7.

Registro de información en la observación

\begin{tabular}{ll}
\hline Periodo & Fecha y hora \\
\hline Anotaciones de observación directa & Organización de los grupos \\
& Clima de trabajo \\
& Comportamientos \\
\hline Anotaciones interpretativas & Motivación \\
& Contraste de opiniones \\
& Liderazgo y colaboración. Rol de los participantes \\
& Incidentes favorables o desfavorables \\
\hline Anotaciones personales & Sensaciones percibidas por el docente en relación al trabajo que \\
& se está desarrollando \\
\hline
\end{tabular}

Fuente: Elaboración propia.

\subsubsection{El grupo de discusión}

Esta técnica se define como una conversación de grupo con un propósito (Albert, 2009). En nuestro caso, se busca confrontar diferentes puntos de vista sobre el proyecto realizado, reflexionar sobre las percepciones que cada participante ha sentido y contrastarlas en grupo, permitiéndonos obtener nuevos puntos de vista y una nueva comprensión de las situaciones vividas. Su aplicación nos permite complementar y completar la información recogida con los otros instrumentos.

\subsubsection{El cuestionario}

Esta técnica es una de las más habituales para recoger información. Albert (2009, p. 115) la define como «una técnica estructurada que permite la recogida rápida y abundante de información mediante una serie de preguntas orales o escritas que debe responder el entrevistado con respecto a una o más variables a medins.

Para la evaluación de nuestro proyecto se ha utilizado un cuestionario estructurado, con preguntas cerradas y dos preguntas abiertas. El cuestionario fue diseñado en lectura fácil, para mejor comprensión de todo el alumnado participante en la experiencia (ver Anexo B).

\subsubsection{Evaluación de los aprendizajes}

Como indica Montanero (2019) en su revisión sobre los métodos pedagógicos emergentes, en el caso del aprendizaje-servicio se echan en falta evidencias sobre los resultados de aprendizaje. Por ello, se realizó una evaluación en esta línea.

Los alumnos y alumnas de Educación Social presentaron un informe final donde exponían los pasos que habían seguido para la construcción de la entrevista utilizada en la selección de personal que realizaron y la evaluación de este instrumento: metodología y resultados. Este informe fue evaluado y calificado por los docentes (la rúbrica utilizada para su evaluación se presenta en el Anexo C).

En el caso del alumnado de Todos Somos Campus, la evaluación para conocer la adquisición de las competencias propuestas se realizó a través de un cuestionario con dos preguntas abiertas y del grupo de discusión (gestionado por la técnico de apoyo).

\section{Resultados}

Los resultados obtenidos se presentan en relación con los objetivos planteados: objetivos de aprendizaje (competencias a adquirir por el alumnado de Educación Social y de Todos Somos Campus) y objetivos del proyecto (desarrollar una experiencia inclusiva en el ámbito universitario, asumiendo 
como reto el hecho de enseñar a estudiantes con características diferentes en un mismo centro y una misma aula).

\subsection{Resultados de aprendiraje}

Los datos sobre resultados de aprendizaje por parte de los estudiantes del Grado de Educación Social obtenidos tras la realización de la evaluación del informe que presentaron los grupos participantes muestran que estos han adquirido las competencias específicas vinculadas a la evaluación: el diseño y elaboración de instrumentos e informe de evaluación con un promedio de 9, siendo la calificación más baja obtenida de 8.5 .

\subsection{Resultados de la experiencia}

El cuestionario ha sido respondido por 42 estudiantes de Grado y por 14 de Todos Somos Campus. Los datos obtenidos nos muestran que esta experiencia ha resultado estimulante para todos ellos, ya que el $100 \%$ del alumnado de Todos Somos Campus ha marcado la opción afirmativa de los ítems y el $100 \%$ de los estudiantes de Grado han respondido afirmativamente a los 7 primeros ítems, observándose la excepción de algún estudiante que no ha respondido a los ítems 8,9 y 10. En cuanto a la pregunta 11 (Qué nota pondrían a las tareas realizadas), se obtiene un promedio de 8.9, siendo mejor valoradas por el grupo de Todos Somos Campus (9.7) que por el grupo de Grado (8.6).

El $100 \%$ de alumnos y alumnas de Todos Somos Campus han respondido estar satisfechos con la participación, las explicaciones, la colaboración con los otros estudiantes y las actividades planteadas. Califican la actividad con un promedio de 9.7. En las preguntas abiertas exponen que lo que más les ha gustado ha sido la colaboración con los compañeros y compañeras, presentarse en las «empresas» y realizar las entrevistas. Entre las cosas que menos les han gustado destacan: pasar vergüenza o tener que hablar en público.

Estas cuestiones se ven reforzadas en el grupo de discusión. Los estudiantes exponen lo agradable de trabajar con otros estudiantes y conocer a otros compañeros de la universidad. Además, la experiencia les ha ayudado a «ver» cómo es una entrevista de trabajo y a sentir que, según sus palabras: «si una entrevista es así, yo puedo hacerlo»; «hacer una entrevista no ha sido tan difícil, las preguntas las respondí bien» $\mathrm{o}$ «me he sentido bien haciendo la entrevista».

En cuanto a los estudiantes de Educación Social, han calificado la experiencia con un 8.6. Las puntuaciones dadas han sido positivas en todos los ítems, exceptuando un participante que no ha calificado los ítems 5,7 y 8 , dos que no han calificado el 9 y uno, el 10. También se cuenta una respuesta negativa en los ítems 8,9 y 10 .

Las respuestas proporcionadas en los ítems abiertos destacan como positivo haber podido colaborar y aprender con los compañeros de Todos Somos Campus, acercándoles al colectivo y permitiéndoles formarse sobre la discapacidad cognitiva, algo que consideran importante para su futuro como educadores sociales. Entre los aspectos que menos les han gustado señalan el poco tiempo del que se ha dispuesto para desarrollar el proyecto (les hubiera gustado contar con más, para poder preparar las cosas) y consideran que se podría mejorar la planificación general.

Estas ideas se han visto reforzadas en el grupo de discusión, donde la idea principal que los estudiantes extraen de la experiencia ha sido lo grato de compartir tareas y aula con personas con discapacidad (la mayoría nunca había tenido contacto con personas de este colectivo) y que se trata de una experiencia importante para su formación como futuros educadores sociales. Algunos expresan que 
este tipo de acciones deberían realizarse más a menudo, pues se aprende más así que con las clases tradicionales (algunos ejemplos se recogen en la Tabla 8).

Tabla 8.

Ejemplos opinión de los estudiantes de Educación Social

\section{OPINIONES EXPRESADAS POR LOS ESTUDIANTES PARTICIPANTES} EN LA EXPERIENCIA

Estudiante 1. «La experiencia me ha aportado un enfoque y una experiencia distinta e innovadora. He podido poner en práctica las cosas aprendidas en clase y poder ser consciente de una realidad distinta a la mía.»

Estudiante 2. «La experiencia me ha enriquecido en mi trayectoria como futura educadora social y como persona. A su vez me ha permitido poner en práctica una evaluación real de lo aprendido en los contenidos teóricos de la asignatura.»

Estudiante 3. «Me ha gustado trabajar conjuntamente, dejando a un lado prejuicios. Es importante que este tipo de experiencias existan.»

Estudiante 4. «Entiendo que actividades como esta deberían tener más cabida en la Facultad ya que se aprende más.»

Estudiante 5. «Nunca había tenido oportunidad de trabajar o estar con personas con discapacidad intelectual y esta experiencia me ha dado la oportunidad de aprender con ellos y de ellos.»

Estudiante 6. «Me hubiera gustado que pudiésemos tener más días para poder compartir y realizar más actividades. Lo recomendaría y repetiría $100 \%$

Fuente: elaboración propia.

En base a la rúbrica de autoevaluación de Puig et al. (2017), tomada como referencia, los diferentes dinamismos analizados presentan niveles de logro aceptables:

- Las necesidades sociales tomadas como punto de partida han invitado a su mejora.

- El servicio ha implicado que los alumnos y alumnas se impliquen de modo altruista y que hayan contribuido a poner solución a la necesidad detectada.

- El sentido del servicio o impacto de la actividad ha sido relevante para todos los participantes, mejorando su sentido cívico.

- El logro de aprendizaje observado ha sido útil e innovador, adquiriendo las competencias exigidas y, además, su implicación en el proyecto.

- La participación, el trabajo en grupo, la reflexión, el reconocimiento y la evaluación han sido continuos, recíprocos, productivos, conjuntos e integrados.

Como excepción figura el partenariado (pues no se asegura la colaboración con otras instituciones) y la consolidación, pues en este caso el aprendizaje-servicio se conoce de modo incipiente y ha sido llevado a cabo por iniciativa de los docentes, siendo, por tanto, una actividad puntual (ver Figura 1).

Figura 1.

Ejemplo de figura

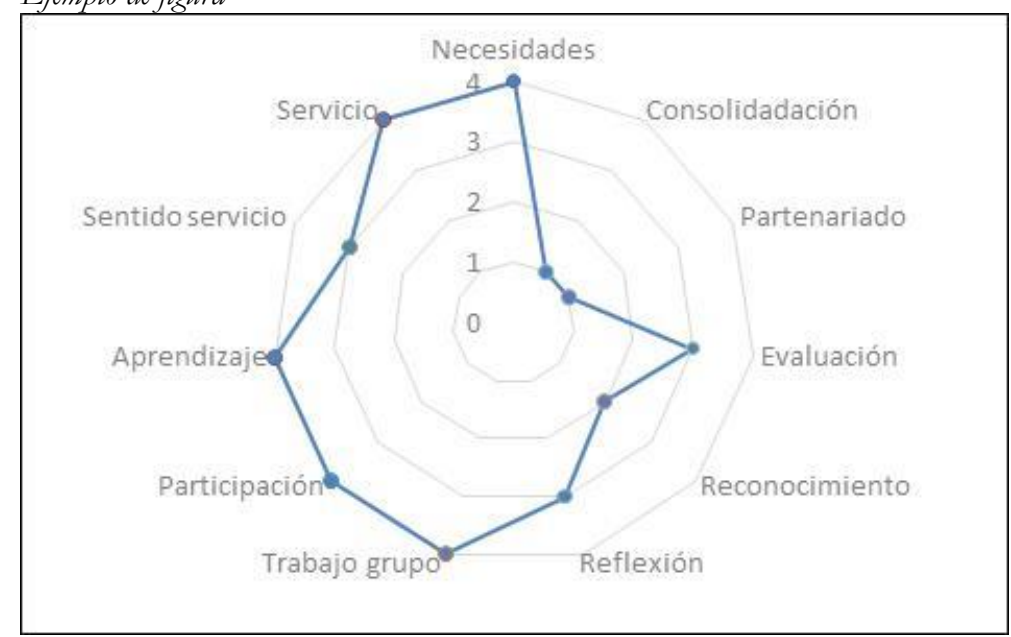

Fuente: elaboración propia. 


\section{Conclusiones}

Tomando las palabras de Puig et al. (2017, p. 124), se dice que una actividad pedagógica vale la pena cuando cumple alguno de los criterios siguientes: la evaluación de los resultados es positiva, el proceso de desarrollo es una experiencia rica para sus protagonistas y, por último, la actividad se inspira en principios que valoramos positivamente.

En este sentido, la evaluación de resultados ha sido positiva, pues la experiencia que se ha llevado a cabo ha aportado, desde la práctica, una mejora del conocimiento y la adquisición de competencias en relación con la evaluación al alumnado de Grado, así como el desarrollo de competencias para afrontar una entrevista al alumnado de Todos Somos Campus.

De igual modo, la experiencia ha resultado rica para sus protagonistas, pues todo el alumnado señala el deseo de que experiencias de este tipo sean llevadas a cabo con mayor frecuencia.

$\mathrm{Y}$, por último, la experiencia aporta valores positivos como la inclusión y la colaboración entre un alumnado diverso. Los estudiantes de Grado han agradecido la posibilidad de participar y colaborar, pues se les ha acercado a compañeros en una situación de discapacidad de la que no tenían conocimiento en muchos casos. Para los estudiantes de Todos Somos Campus ha supuesto una inclusión plena como alumnado universitario, compartiendo aulas y tarea, valorándose su colaboración. También es cierto que, como explica Deeley (2016) y sucede con cualquier otra metodología, el hecho de utilizar metodologías como el ApS no es garantía de éxito. Sin embargo, coincidimos con Aramburuzabala et al. (2015) en que esta metodología «se muestra como una estrategia pedagógica que compromete a los estudiantes en el servicio para mejorar la comprensión de los conceptos académicos a través de un aprendizaje práctico» (p. 90), al menos así lo confirman los resultados y la satisfacción expresada por el alumnado.

Estos resultados también coinciden con los obtenidos por Cerrillo et al. (2013). Las autoras desarrollan un programa de inclusión de alumnado con discapacidad intelectual en la Universidad Autónoma de Madrid y refieren en sus resultados que la opinión de los estudiantes que tienen contacto con el colectivo con discapacidad intelectual cambia en relación con las «capacidades» y la «integración socials. Y los estudiantes del colectivo con discapacidad muestran agradecimiento, se sienten privilegiados por la oportunidad brindada, orgullosos porque son «universitarios». Se logra su empoderamiento.

Además, con la aplicación de metodología ApS se ha trabajado para conseguir un aprendizaje holístico, que suma teoría y práctica (Ruiz y García, 2019), con parte cognitiva y afectiva (Deeley, 2016), a través de una experiencia activa (Capella et al., 2018), trabajando de forma comprometida y reflexiva (Montanero, 2019), confirmando la obtención de resultados exitosos.

Nos sentimos satisfechos del logro alcanzado, no solo en cuanto a resultados de aprendizaje, los cuales son importantes, sino en mayor medida por resultar una actividad que ha logrado el empoderamiento de nuestros estudiantes, que crean que son capaces de lograr cosas, sobre todo los alumnos y alumnas con discapacidad intelectual, los cuales en muchos casos tienen una autopercepción de sus posibilidades baja y dudan de sus posibilidades para afrontar o resolver determinadas situaciones.

No obstante, también se deben reconocer las limitaciones encontradas en el camino, como por ejemplo: el tiempo para la colaboración entre grupos, así como para la planificación de la experiencia (queja expresada por el alumnado), o los instrumentos elaborados para la evaluación y recogida de resultados, que, si bien se ha buscado una triangulación que permita una comparación múltiple, es cierto que no cuentan con la validez y fiabilidad deseadas metodológicamente.

Por ello, algunas de las propuestas de mejora sugeridas son:

- Incremento del tiempo/sesiones a desarrollar, de modo que la colaboración entre los estudiantes pueda realizarse durante más tiempo, lo que permitiría un mayor conocimiento e integración de los grupos.

- Revisión de los instrumentos utilizados en la evaluación para que los datos que recojan puedan considerarse más fiables y válidos, así como ser trasladados a otras experiencias de carácter similar.

- Invitar a un mayor número de profesores para desarrollar experiencias similares en colaboración con otras materias de modo que se abarque un mayor número de competencias a trabajar. 
Esto permitirá, también, confirmar si la utilización de la metodología ApS ofrece resultados igual de satisfactorios en todas ellas.

Anexo A. Tabla de contenidos del 1er curso Todos Somos Campus II, distribuidos por bloques

\begin{tabular}{|c|c|}
\hline BLOQUES & CONTENIDOS \\
\hline $\begin{array}{l}\text { BLOQUE 0: } \\
\text { INTRODUCCIÓN }\end{array}$ & $\begin{array}{l}\text { Inclusión y participación social } \\
\text { - } \quad \text { La vida comunitaria (conocimiento y utilización de recursos } \\
\text { comunitarios, accesibilidad universal en la comunidad, Ley de } \\
\text { Accesibilidad, educación vial, educación medioambiental, valo- } \\
\text { res). } \\
\text { - } \quad \text { Derechos y deberes de las personas con discapacidad intelec- } \\
\text { tual como ciudadanos de pleno derecho (el marco legal, toma } \\
\text { de decisiones). }\end{array}$ \\
\hline $\begin{array}{l}\text { BLOQUE I: } \\
\text { DESARROLLO PERSO- } \\
\text { NAL Y AUTONOMÍA }\end{array}$ & 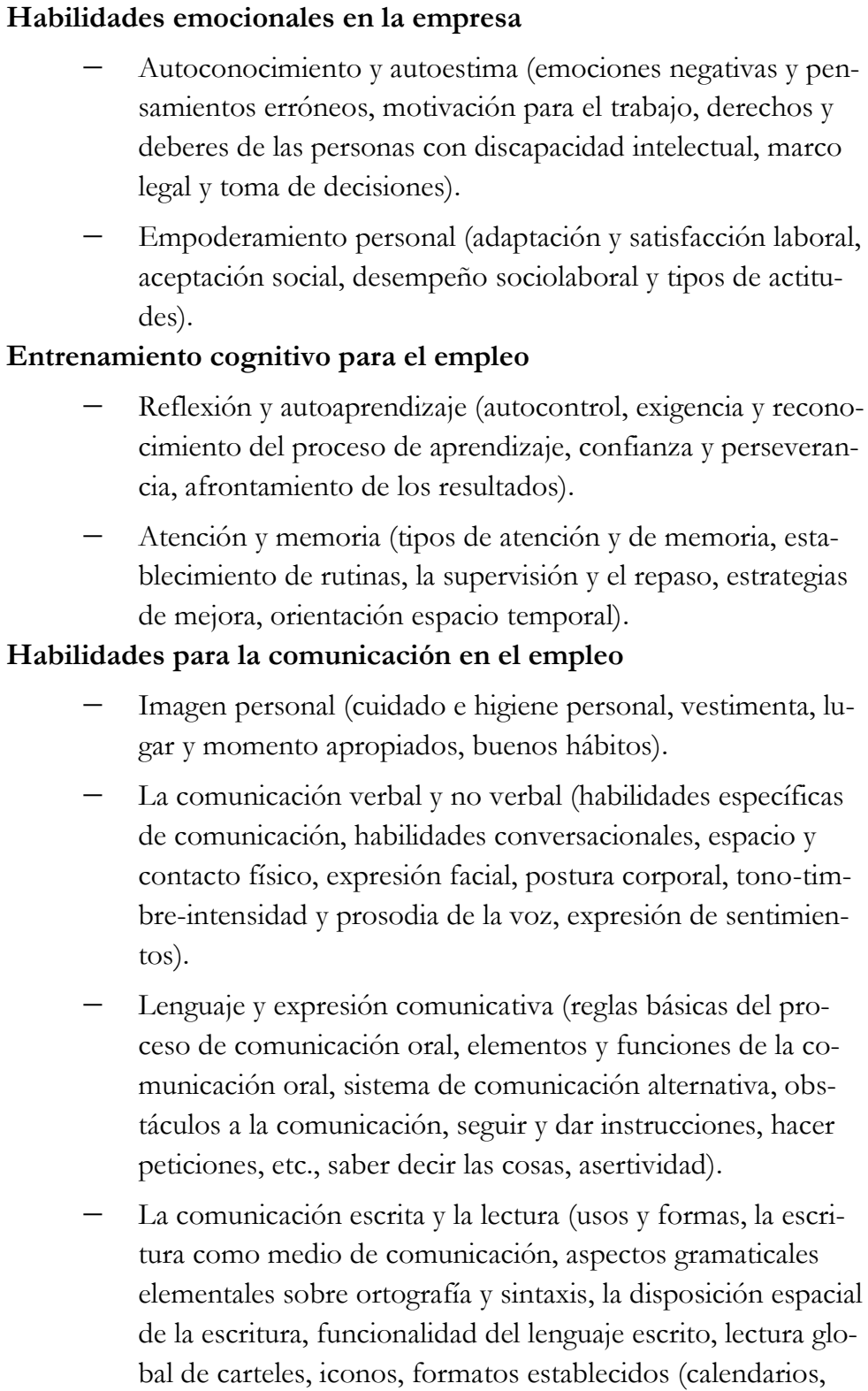 \\
\hline
\end{tabular}




\begin{tabular}{|c|c|}
\hline BLOQUES & CONTENIDOS \\
\hline & $\begin{array}{l}\text { horarios, instancias, nombres y apellidos, etc.), reglas de ela- } \\
\text { boración de textos en Lectura Fácil, lectura comprensiva: la } \\
\text { palabra, la frase, el párrafo, etc., la lectura como su uso, en- } \\
\text { tretenimiento y disfrute). } \\
\text { Habilidades sociales en el entorno de trabajo } \\
\text { - } \quad \text { Iniciativa y participación (habilidades sociales básicas, nor- } \\
\text { mas de cortesía, ritmo de trabajo, rendimiento, calidad y acti- } \\
\text { tud cooperativa y de ayuda, conocimiento del grupo). } \\
\text { - } \quad \text { Liderazgo (relación con el líder, seguimiento de instruccio- } \\
\text { nes, tipos de liderazgo, jerarquías, vinculación con el organi- } \\
\text { grama). }\end{array}$ \\
\hline $\begin{array}{l}\text { BLOQUE II: } \\
\text { FORMACIÓN PARA EL } \\
\text { EMPLEO }\end{array}$ & 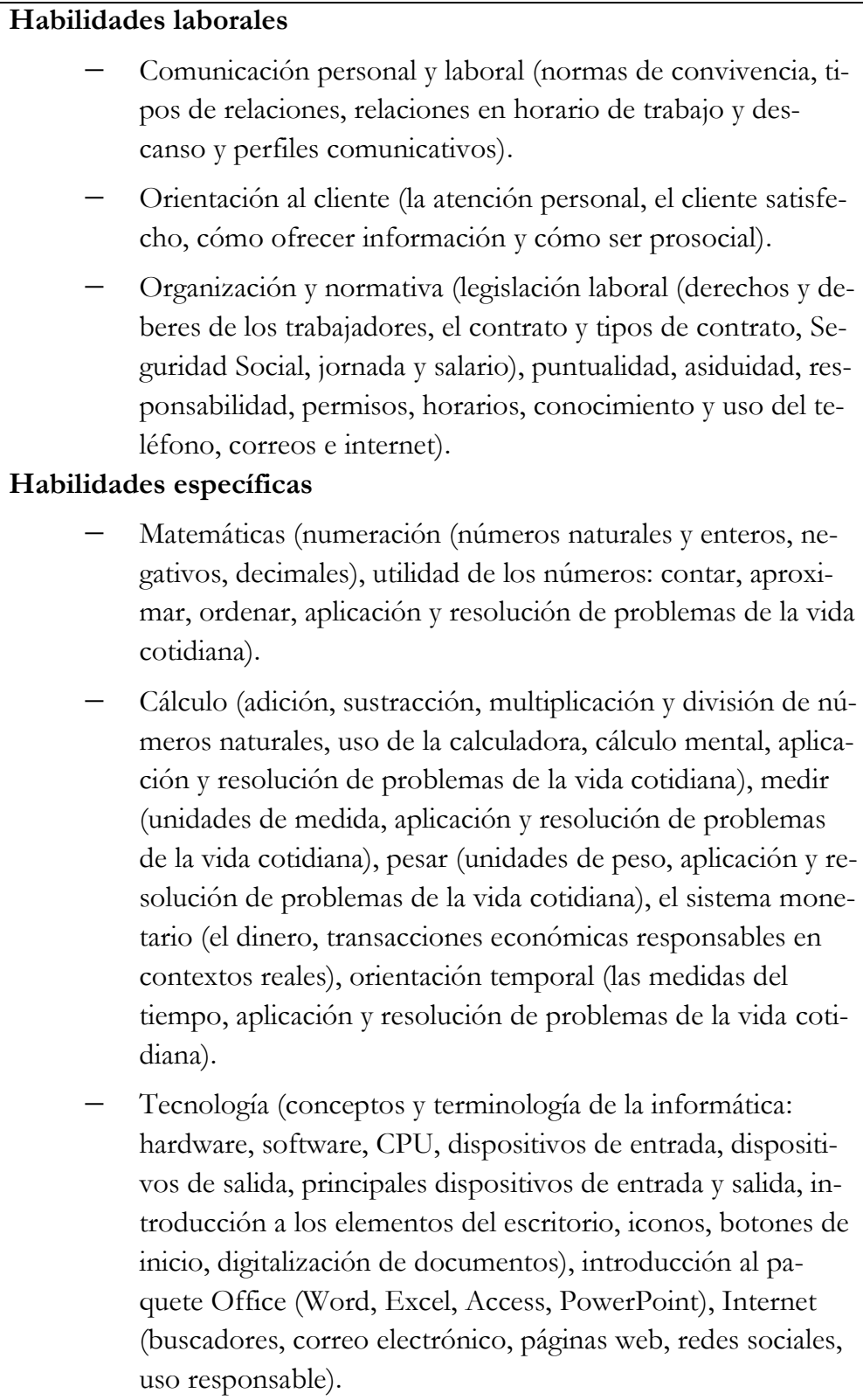 \\
\hline $\begin{array}{l}\text { BLOQUE III: } \\
\text { DESARROLLO PROFE- } \\
\text { SIONAL GENERAL Y } \\
\text { ESPECÍFICO. ÁREA DE }\end{array}$ & $\begin{array}{l}\text { Orientación vocacional laboral básica } \\
\quad-\quad \text { Preferencias profesionales, proyecto personal y profesional, } \\
\text { toma de decisiones). }\end{array}$ \\
\hline
\end{tabular}




\begin{tabular}{|c|c|}
\hline BLOQUES & $\mathrm{DS}$ \\
\hline $\begin{array}{l}\text { FORMACIÓN ESPECIA- } \\
\text { LIZADA ORIENTADA } \\
\text { AL EMPLEO }\end{array}$ & $\begin{array}{l}\text { - Formación para el empleo (oferta formativa de la Región de } \\
\text { Murcia), búsqueda de información, etc. } \\
\text { Desarrollo profesional específico } \\
\text { - } \quad \text { Operaciones de Auxiliares de Servicios (tramitación, de co- } \\
\text { rrespondencia y paquetería, control de almacén de material } \\
\text { de oficina y reprografía, operaciones básicas de tesorería, co- } \\
\text { municación telefónica en el ámbito profesional, recepción de } \\
\text { personas externas a la organización, archivo de documentos, } \\
\text { reprografía de documentos, integración y comunicación en el } \\
\text { centro de trabajo). } \\
\text { - } \quad \text { Aproximación a las diferentes ocupaciones y puestos de tra- } \\
\text { bajo ofertados en el Prácticum. } \\
\text { Formación individualizada orientada al empleo (2 cr) } \\
\text { - } \quad \text { Búsqueda de empleo, planificación inicial para la búsqueda } \\
\text { de empleo: recursos útiles y definición de objetivos y elabora- } \\
\text { ción de un plan de acción, herramientas para la búsqueda de } \\
\text { empleo. } \\
\text { - } \quad \text { Curriculum: tipos de CV, elaboración de CV personal. } \\
\text { - } \quad \begin{array}{l}\text { Entrevista de trabajo: las claves para afrontar una entrevista } \\
\text { de trabajo, simulación de entrevistas de trabajo con los estu- }\end{array} \\
\text { diantes. }\end{array}$ \\
\hline $\begin{array}{l}\text { BLOQUE IV: } \\
\text { PRÁCTICAS DE EM- } \\
\text { PLEO CON APOYO }\end{array}$ & $\begin{array}{l}\text { Se les proporcionarán experiencias de prácticas formativas, utilizando la } \\
\text { metodología de empleo con apoyo, dentro del ámbito universitario y/o } \\
\text { empresarial en las siguientes ocupaciones: } \\
\text { - Auxiliar de archivo } \\
\text { - Auxiliar de información } \\
\text { - Auxiliar de servicios generales } \\
\text { - Auxiliar de venta } \\
\text { - Clasificador y/o repartidor de correspondencia } \\
\text { - Empleado de reposición } \\
\text { - Operario de acabados de reprografía } \\
\text { - Operario de reprografía } \\
\text { - Ordenanza } \\
\text { - Preparador de pedidos } \\
\text { - Telefonista en servicios centrales de información }\end{array}$ \\
\hline
\end{tabular}

Anexo B. Cuestionario elaborado para evaluar la experiencia desarrollada

\section{CUESTIONARIO DE EVALUACION ACTIVIDAD}


NOMBRE Y APELLIDOS DEL ALUMNO/A:

FECHA:

Responde a las siguientes preguntas marcando con una $X$ lo que se indica

1. La participación en el aula me ha gustado

Sí No

2. Mis compañeros y compañeras me han explicado bien la actividad

Sí No

3. Mis compañeros y compañeras han escuchado mis opiniones

Sí No

4. Mis compañeros y compañeras han respondido siempre a mis dudas

Sí No

5. Mis compañeros y compañeras me han animado a participar

Sí No

14

6. Mis compañeros y compañeras me han tratado con respeto

Sí No

14

7. Las tareas me han gustado

Sí No

14

8. Los profesores me han animado a participar

Sí No

140

9. Los profesores han resuelto mis dudas

Sí No

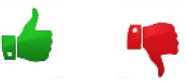

10. Los profesores se han preocupado de que aprenda

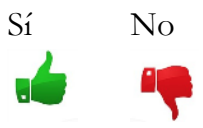

11. ¿Qué nota le pondrías a las actividades realizadas?

Del 0 al 10

Di qué cosas te han gustado más y cuáles te han gustado menos: 
Anexo C. Rúbrica de evaluación de los aprendizajes de los estudiantes de E. Social: evaluación del informe que deben elaborar

\begin{tabular}{|l|l|}
\hline \multicolumn{1}{|c|}{ INDICADORES } & PUNTUACIÓN \\
\hline Presentación del trabajo y comunicación** & De 0 a 2 \\
\hline $\begin{array}{l}\text { Ajuste del contenido a lo exigido en la tarea* } \\
\text { Uso de referencias y citas a autores, artículos, webs, etc. en la argumenta- } \\
\text { ción }\end{array}$ & De 0 a 7 \\
\hline Calificación de la tarea 0 a 1 \\
\hline
\end{tabular}

\begin{tabular}{|c|c|c|c|c|c|}
\hline \multicolumn{5}{|c|}{ *AJUSTE DEL CONTENIDO A LO EXIGIDO EN LA TAREA } & Puntos \\
\hline $\begin{array}{l}\text { CONOCIMIENTO In- } \\
\text { formación que se aporta } \\
\text { en relación a la evalua- } \\
\text { ción. Relación con la } \\
\text { teoría. Aplicación de } \\
\text { esta a la práctica. } \\
\text { Justificación del instru- } \\
\text { mento de evaluación. }\end{array}$ & $\begin{array}{l}\text { No men- } \\
\text { ciona infor- } \\
\text { mación parti- } \\
\text { cular }\end{array}$ & $\begin{array}{l}\text { Proporciona } \\
\text { muy poca in- } \\
\text { formación }\end{array}$ & $\begin{array}{l}\text { Proporciona } \\
\text { alguna infor- } \\
\text { mación }\end{array}$ & $\begin{array}{l}\text { Proporciona } \\
\text { gran infor- } \\
\text { mación }\end{array}$ & $0-2$ \\
\hline $\begin{array}{l}\text { RAZONAMIENTO } \\
\text { Enfoque del tema cohe- } \\
\text { rente, ajuste adecuado } \\
\text { entre objetivo y desarro- } \\
\text { llo. Emisión de juicio de } \\
\text { valor. }\end{array}$ & $\begin{array}{l}\text { Se divaga sin } \\
\text { precisar nin- } \\
\text { gún aspecto }\end{array}$ & $\begin{array}{l}\text { Apenas men- } \\
\text { ciona algún } \\
\text { tema de } \\
\text { comparación }\end{array}$ & $\begin{array}{l}\text { Describe los } \\
\text { temas a com- } \\
\text { parar y pro- } \\
\text { porciona va- } \\
\text { rios ejemplos }\end{array}$ & $\begin{array}{l}\text { Claramente } \\
\text { define los tó- } \\
\text { picos de } \\
\text { compara- } \\
\text { ción, propor- } \\
\text { cionando de- } \\
\text { talles especí- } \\
\text { ficos }\end{array}$ & $0-2$ \\
\hline $\begin{array}{l}\text { EJECUCIÓN } \\
\text { Coherencia entre el ins- } \\
\text { trumento diseñado y la } \\
\text { información que se pre- } \\
\text { tende obtener. } \\
\text { Construcción adecuada } \\
\text { (ítems) para la muestra a } \\
\text { la que se dirige y el } \\
\text { tiempo disponible. }\end{array}$ & $\begin{array}{l}\text { No existe } \\
\text { adecuación }\end{array}$ & $\begin{array}{l}\text { Apenas } \\
\text { existe }\end{array}$ & $\begin{array}{l}\text { Existe cohe- } \\
\text { rencia en la } \\
\text { construcción } \\
\text { pero no se } \\
\text { adecúa co- } \\
\text { rrectamente }\end{array}$ & $\begin{array}{l}\text { Claramente } \\
\text { hay coheren- } \\
\text { cia y se ade- } \\
\text { cua a lo plan- } \\
\text { teado en el } \\
\text { objetivo }\end{array}$ & \\
\hline \multicolumn{6}{|l|}{ **COMUNICACIÓN } \\
\hline $\begin{array}{l}\text { Claridad, organización } \\
\text { de la información, expo- } \\
\text { sición, coherencia de ar- } \\
\text { gumentos. }\end{array}$ & $\begin{array}{l}\text { El trabajo } \\
\text { carece de } \\
\text { tema central } \\
\text { y una se- } \\
\text { cuencia ló- } \\
\text { gica, es difícil } \\
\text { de entender }\end{array}$ & $\begin{array}{l}\text { El tema ex- } \\
\text { presado es } \\
\text { confuso y no } \\
\text { fácil de en- } \\
\text { tender }\end{array}$ & $\begin{array}{l}\text { Desarrollan } \\
\text { una secuen- } \\
\text { cia lógica que } \\
\text { permite } \\
\text { comprender } \\
\text { la tarea }\end{array}$ & $\begin{array}{l}\text { Las partes } \\
\text { están integra- } \\
\text { das en una } \\
\text { secuencia ló- } \\
\text { gica que faci- } \\
\text { lita su com- } \\
\text { prensión }\end{array}$ & $0-2$ \\
\hline $\begin{array}{l}\text { Limpieza, formato y or- } \\
\text { tografía adecuadas. }\end{array}$ & & & & & \\
\hline
\end{tabular}




\section{Referencias}

Albert, M. J. (2009). La investigación educativa. Claves teóricas. Madrid: Mc Graw Hill.

Álvarez, J. L., Martínez, M. J., González, H., \& Buenestado, M. (2017). El aprendizaje-servicio en la formación del profesorado de las universidades españolas. Revista Española de Pedagogía, 75 (267), pp. 199-217. doi: 10.22550/REP75-2-2017-02.

Aramburuzubala, P. (2013). Aprendizaje-servicio: una herramienta para educar desde y para la justicia social. Revista Internacional de Educación para la Justicia Social, 2(2), pp. 5-11.

Aramburuzabala, P., Cerrillo, R., \& Tello, I. (2015). Aprendizaje-servicio: una propuesta metodológica para la introducción de la sostenibilidad curricular en la universidad. Profesorado. Revista Currículum y Formación del Profesorado, 19(1), pp. 73-95.

Batlle, R. (2011). ¿De qué hablamos cuando hablamos de aprendizaje-servicio? Crítica, 972, pp. 4954.

Capella, C., Zorrilla, L., \& Gil, J. (2018). Aproximación al aprendizaje-servicio como método pedagógico. En O. Chiva, \& J. Gil (Eds.) Aprendizaje-servicio universitario. Modelos de intervención e investigación en la formación inicial docente (pp. 15-25). Barcelona,: Octaedro.

Cerrillo, R., Izuzquiza, D., \& Egido, I. (2013). Inclusión de jóvenes con discapacidad intelectual en la universidad. Revista de Investigación en Educación, 11(1), pp. 41-57.

Comisión Europea (2010). Estrategia Europea sobre Discapacidad 2010-2020: un compromiso renovado para una Europa sin barreras. COM(2010) 636 final. Bruselas, Bélgica. Unión Europea. Recuperado de: https:/ / eur-lex.europa.eu/LexUriServ/LexUriServ.do?uri=COM:2010:0636:FIN:es:PDF.

Deeley, S. J. (2016). El aprendizaje-servicio en educación superior. Teoría, práctica y perspectiva crítica. Madrid: Narcea.

Díaz, A. (2012). La formación cultural: una propuesta sobre cómo asumirla y estudiarla. Íkala, 17(3), pp. 223-229.

Fernández, T., \& Ponce de León, L. (2016). Elaboración, gestión y evaluación de proyectos sociales. Madrid, España: Pirámide.

Fernández, I., Veliz, V. F., \& Ruiz, A. I. (2016). Hacia una pedagogía inclusiva. Revista electrónica Educare, 20(3), pp. 1-15. doi: 10.15359/ree.20-3.13

Folgueiras, P., Luna, E., \& Puig, G. (2010). Aprendizaje y servicio: estudio del grado de satisfacción de estudiantes universitarios. Revista de Educación, 362, pp. 159-185. doi: 10.4438/1988-592X-RE2011-362-157

García, M., \& Benítez, R. (2014). Comprometiéndonos con «nuestra escuela»: un proyecto de aprendizaje-servicio para una formación del profesorado inclusiva. Revista Nacional e Internacional de Educación Inclusiva, 7(2), pp. 69-83.

García, J. M., De la Calle, C., Valbuena, M. C., \& De Dios, T. (2016). Hacia la validación del constructo «Responsabilidad social del estudiante universitario» (RSEU). Bordón. Revista de Pedagogía, 68(3), pp. 41-58. doi: 10.13042/Bordon.2016.68303

Gil, J. (2012). La evaluación del aprendizaje en la universidad según la experiencia de los estudiantes. Estudios Sobre Educación, 22, pp. 133-153.

González, J. L., Jover, G., \& Martínez, M. (2017). La ética del aprendizaje servicio en la universidad: una interpretación desde el pragmatismo. Bordón. Revista de Pedagogía, 69(4), pp. 63-78. doi: 10.13042/Bordon.2017.690405.

Mateo, J., \& Vlachopoulos, D. (2013). Reflexiones en torno al aprendizaje y a la evaluación en la universidad en el contexto de un nuevo paradigma para la educación superior. Educación XXI, 16(2), pp. 183-208. doi: 10.5944/educxxI.16.2.2639

Mayor, D., \& Rodríguez, D. (2016). Aprendizaje-servicio y práctica docente: una relación para el cambio educativo. Revista de Investigación Educativa, 34(2), pp. 535-552. doi: 10.6018/rie.34.2.231401

Medía, R. (2016). El aprendizaje-servicio: una metodología para la innovación educativa. Revista CONVTVEZ, 16, pp. 1-16.

Mendía, R. (2012). El aprendizaje-servicio como una estrategia inclusiva para superar las barreras de aprendizaje y la participación. Revista Educación Inclusiva, 5(1), pp. 71-82.

Montanero, M. (2019). Métodos pedagógicos emergentes para un nuevo siglo: ¿qué hay realmente de innovación? Teoría de la Educación. Revista Interuniversitaria, 31(1), pp. 5-34. doi: $10.14201 /$ teri.19758 
Ochoa, A., Pérez, L. M., \& Salinas, J. J. (2018). El aprendizaje-servicio (APS) como práctica expansiva y transformadora. Revista Iberoamericana de Educación, 76, pp. 15-34. doi: 10.35362/rie7602846

Pérez, G. (2011). Investigación cualitativa. Retos e interrogantes. Madrid: La Muralla.

Piñana, E. (2018). Experiencia educativa de aprendizaje-servicio en Educación Primaria: Gota a Gota. Tendencias Pedagógicas, 32, pp. 193-201. doi: 10.15366/tp2018.32.014

Puig, J. M. (2015). ¿Cómo realizar un proyecto de aprendizaje servicio? 11 ideas clave. Barcelona, España: Graó.

Puig, J. M., Martín, X., \& Rubio, L. (2017). ¿Cómo evaluar proyectos de aprendizaje-servicio? Voces de la Educación, 2 (4), pp. 122-132.

Rodríguez, P., De la Herrán, A., \& Cortina, M (2015). Pedagogía de la muerte mediante aprendizaje servicio. Educación XX1, 18(1), pp. 189-212. doi: 10.5944/edu-cXX1.18.1.12317

Ruiz, M., \& García, J. (Eds.) (2019). Aprendizaje-servicio. Los retos de la evaluación. Madrid, España: Narcea.

Santamaría, I., \& Martínez, A. (2018). El aprendizaje servicio, interculturalidad y justicia social: experiencias disruptivas y transformadoras con futuras maestras de educación infantil y primaria. Revista Qurriculum, 31, pp. 97-118. doi: 10.25145/j.qurricul.2018.31.005

Silva, J., \& Maturana, D. (2017). Una propuesta de modelo para introducir metodologías activas en educación superior. Innovación educativa, 17(73), pp. 117-131

Vázquez, S., Liesa, M., \& Lozano, A. (2017). Recreos cooperativos e inclusivos a través de la metodología de Aprendizaje-Servicio. Revista electrónica interuniversitaria de formación del profesorado, 20(1), pp. 173-185. doi: 10.6018/reifop.20.1.213181

Vergara, D. (2012). Una experiencia educativa de aprendizaje cooperativo en la universidad. Profesorado. Revista de currículum y formación del profesorado, 16(2), pp. 387-402. 